\title{
Gestión Sustentable De Riesgos Y Crisis En El Turismo Mexicano Y Latinoamericano Como Problema Estratégico Para La Seguridad De Los Destinos. Implicaciones Para Ciudad Juárez, México
}

\author{
Dr. Manuel Ramón González Herrera \\ Programa de Licenciatura en Turismo. Instituto de Ciencias Sociales y \\ Administrativas. Universidad Autónoma de Ciudad Juárez. México
}

MSc. Mercedes de los Ángeles Rodríguez Rodríguez

Facultad de Geografía e Historia. Universidad de Las Palmas de Gran

Canaria. España

doi: 10.19044/esj.2016.v12n11p183 URL:http://dx.doi.org/10.19044/esj.2016.v12n11p183

\begin{abstract}
The integrated management of risk and crisis in tourism has recently been incorporated to scientific debate and therefore to the practical management; which is why concepts and procedures are required to gain efficiency and practical operational development. The aim of this study is to justify the sustainable management process of risk and crisis in Mexican and Latin American tourism as a strategy for the security of destinations, and identify the experiences that promote a better preparedness and planning of risk and crisis caused by insecurity in Ciudad Juarez. The results of this study demonstrate that the integrated management of risk and crisis on tourism is justified as a strategic problem for security in tourist destinations, as well as the necessity to have policy and institutional framework to manage tourism safety. Then as a learning experience, an analysis of crisis and management strategies related to unsafe destinations in Latin America and Mexico are presented. Finally, the strategic projection for the preparation and planning of tourism, facing risks and crisis caused by insecurity in Ciudad Juarez is proposed. This includes the characterization of the city as an insecure cross-border tourist destination, the formulation of the strategic problem, the development of the principles to form a Sustainable and Secure Tourism System, and the planning of action areas for short-term and longterm implementation.
\end{abstract}

Keywords: Risks, crisis, tourism, sustainable, management, security 


\section{Resumen}

La gestión integrada de riesgos y crisis en el turismo es un tema de reciente incorporación al debate científico y por tanto a la gestión práctica, por lo que se requiere un desarrollo conceptual y procedimental para ganar en eficiencia y operatividad práctica. El objetivo de este estudio es justificar el proceso de gestión sustentable de riesgos y crisis en el turismo mexicano y latinoamericano como problema estratégico para la seguridad de los destinos e identificar las experiencias que favorezcan el mejoramiento de la preparación y planificación de riesgos y eventos de crisis provocados por la inseguridad en Ciudad Juárez. Como resultado se demuestra que la gestión integrada de riesgos y crisis en el turismo es un problema estratégico de seguridad en los destinos, así como la necesidad de disponer de un marco institucional e instrumental para la gestión de la seguridad turística. Seguidamente se presenta un análisis de situaciones de crisis y estrategias de gestión en destinos inseguros de Latinoamérica y México como experiencia de aprendizaje. Finalmente, se realiza la proyección estratégica para la preparación y planificación del turismo en Ciudad Juárez ante riesgos y crisis provocadas por inseguridad, en función de lo cual se caracteriza la ciudad como espacio de turismo fronterizo en un entorno de inseguridad, se formula el problema estratégico, se elaboran los principios para conformar un Sistema de Turismo Seguro Sustentable, y se proyectan ámbitos de actuación con las acciones a implementar.

Palabras clave: Riesgos, crisis, turismo, sustentable, gestión, seguridad

\section{Introducción}

La Organización Mundial de Turismo ha destacado el valor de este sector global "como una actividad esencial de las sociedades modernas y factor determinante de la calidad de vida, por lo que los gobiernos deben actuar en favor de la paz y la seguridad, las cuales son imprescindibles para el desarrollo del turismo, al tiempo que la seguridad es uno de los derechos fundamentales de todas las personas, una obligación indelegable del Estado y un requisito indispensable para la competitividad y la sustentabilidad del turismo”, a la vez que la “aplicación de políticas públicas en materia de seguridad turística es de gran importancia para el afianzamiento del proceso de integración regional” (IDT, 2010: 51-52; OMT, 2013).

Precisamente, la seguridad de los destinos es un indicador del nivel de sustentabilidad turística (GSTC, 2013; 2014). Por ello, la gestión sustentable de riesgos y crisis en el turismo mexicano y latinoamericano debe ser abordada como un problema estratégico para la seguridad de los destinos. De tal forma, se convierte en una necesidad el estudio y reflexión crítica de los conceptos, enfoques metodológicos y conocimientos prácticos 
sobre la realidad en que se desarrolla el turismo en términos de seguridad. Consecuentemente, el crecimiento y la prosperidad del desarrollo turístico deben ser asociados a la minimización de los riesgos y eventos de crisis condicionados por la violencia y falta de paz, ya que la seguridad es uno de los criterios utilizados por los turistas para seleccionar el destino de viaje (CESTUR, 2012: 189).

Paradójicamente, según el Instituto para la Economía y la Paz, el mundo se está haciendo cada vez menos pacífico, y por tanto más inseguro; al tiempo que le está costando más a la economía global por concepto de gasto en la violencia, lo cual se hace evidente al reportar que en el año 2014 el impacto de la violencia alcanzó US\$14.3 trillones. Destaca que Estados Unidos, China, Rusia, India y Brasil representan la mayor cantidad de gastos relacionados con la violencia, lo que equivale al 54\% del gasto global para gestionarla. Agrega que si el mundo redujera el gasto por la violencia en $10 \%$, se generarían US\$1.4 trillones, lo cual apoyaría la recuperación económica global, incrementaría el desarrollo y serviría de alivio a quienes viven en la pobreza extrema (IEP, 2015b).

Resulta por tanto oportuno abordar desde el punto de vista investigativo la comprensión del impacto de estas situaciones de retroceso en los niveles de paz y violencia sobre los destinos turísticos con un enfoque holístico. La literatura expone que en muchos casos el turismo ha sufrido un descenso inesperado y repentino de la demanda; así por ejemplo, la desaceleración de la demanda turística en los Estados Unidos después del 11 de septiembre de 2001 fue un caso particular de eventos catastróficos de crisis en el turismo, ante el cuál y en ausencia de investigaciones sobre las respuestas más convenientes, los tomadores de decisiones se enfrentaron a un escenario de incertidumbre (Blake, et al., 2002).

Ante esta problemática es oportuno cuestionarse los niveles actuales de planificación y preparación del sector turístico mexicano y latinoamericano para enfrentar las crisis e identificar las estructuras organizacionales, así como la asignación de recursos suficientes. Se advierte en términos generales falta de alternativas para la planificación y preparación ante los riesgos y eventos de crisis en el turismo y una visión a corto plazo, en la que la gestión de los destinos y sus organizaciones, y la investigación científica no responden aún a tan complejo problema, a la vez que las crisis económicas y financieras siguen recibiendo la mayor atención. Esto a pesar de los múltiples esfuerzos realizados en el ámbito internacional, como la propuesta de agendas y otros instrumentos que facilitan la investigación y generación de nuevos conocimientos a favor de la gestión de las crisis en el turismo.

Tomando en consideración esta compleja y polémica problemática se enuncian las siguientes interrogantes de investigación con el propósito de 
generar posibles respuestas: ¿Es la inseguridad un factor limitativo para la gestión estratégica de la sustentabilidad de los destinos turísticos y sus organizaciones? ¿Qué argumentos y oportunidades justifican la gestión sustentable de riesgos y crisis en el turismo mexicano y latinoamericano? ¿Cuáles son las implicaciones de la gestión sustentable de riesgos y crisis para la conformación de un sistema de turismo más seguro en Ciudad Juárez, México?

En consecuencia es objetivo general de la presente investigación justificar el proceso de gestión sustentable de riesgos y crisis en el turismo mexicano y latinoamericano como problema estratégico para la seguridad de los destinos e identificar las experiencias que favorezcan el mejoramiento de la preparación y planificación ante riesgos y eventos de crisis provocados por la inseguridad en Ciudad Juárez. Derivado del objetivo general se formulan como objetivos específicos: Fundamentar la gestión integrada de riesgos y crisis como un problema estratégico para la seguridad del turismo mexicano y latinoamericano; examinar las mejores prácticas relacionadas con la gestión de las crisis en el turismo de México y América Latina atendiendo a los criterios de planificación, procedimientos de comunicación y preparación de los destinos/organizaciones; y sistematizar experiencias de gestión de riesgos y crisis provocadas por eventos de inseguridad en México y Latino América con el fin de servir de aprendizaje para mejorar la preparación y planificación del turismo en Ciudad Juárez.

Los resultados justifican el posicionamiento de la gestión integrada de riesgos y crisis en el turismo como problema estratégico de seguridad a nivel de destinos, reconociendo las características del contexto latinoamericano con respecto a la relación paz-turismo; así como el marco institucional e instrumental para la gestión de riesgos y crisis según oportunidades que ofrecen a la seguridad turística. Seguidamente se presenta un análisis de situaciones de crisis y estrategias de gestión en destinos inseguros de Latinoamérica y México como experiencia de aprendizaje para la región y antecedente al caso de estudio. Finalmente, se realiza la proyección estratégica para la preparación y planificación del turismo en Ciudad Juárez ante riesgos y crisis provocadas por inseguridad; aquí se caracteriza la ciudad como espacio de turismo fronterizo en un entorno de inseguridad, se formula el problema estratégico, se construyen los principios para conformar un Sistema de Turismo Seguro Sustentable; y se proyectan ámbitos de actuación con acciones a implementar.

\section{Revisión de la literatura}

\section{Sustentabilidad turística y Seguridad}

Una de las motivaciones más fuertes en el turismo actual es el interés creciente por el ambiente natural y el patrimonio cultural (Edgell, et al., 
2013), lo cual constituye una oportunidad para promover la sustentabilidad, a la vez que demanda una apropiada seguridad para satisfacer las expectativas de estos segmentos de mercado. Según el Centro para la Sustentabilidad de la Universidad del Este de Carolina (En: Edgell, et al., 2013:149) el turismo sustentable contribuye a una economía más equilibrada mediante la generación de empleos, ingresos e impuestos, al tiempo que protege y mejora los recursos culturales, históricos, naturales y construidos para el disfrute y bienestar de residentes y visitantes. Por ende, los destinos turísticos que implementan la sustentabilidad adicionan una dimensión especial al crecimiento económico y a la calidad de vida de la comunidad (Edgell, et al., 2013:155).

Ante el problema de certidumbre de la sustentabilidad se han desarrollado instrumentos que contienen diversos indicadores y criterios de medición. La propuesta y utilización de los indicadores de sustentabilidad en el Turismo de México se ha basado en la metodología SECTUR avalada por la OMT; la misma ha sido implementada a través de la Agenda 21 Local para municipios turísticos con un enfoque integrador, y permite medir y monitorear las condiciones de cada destino; esto mediante la evaluación periódica de la sustentabilidad del turismo, considerando las diferencias que existen entre los mismos (Ibáñez, 2010). Uno de los principales instrumentos desarrollado como parte de las Agendas 21 turísticas es el Sistema de Indicadores de Sustentabilidad, el cual se ha aplicado según referencia teórica en más de 72 importantes destinos turísticos del país (SECTUR, 2008; En: Ibáñez, 2010).

En la práctica los modelos de desarrollo turístico sustentable surgen como un constructo conceptual alternativo a los modelos de desarrollo turístico tradicional, con los cuales se ha asociado un alto fondo de impactos adversos. Su fundamento se apoya en el paradigma de la sustentabilidad, el cual "presupone" una equilibrada integración entre las dimensiones económica, ambiental y social del desarrollo turístico. En opinión de C. Virgen "el desarrollo humano se transforma en un elemento central del paradigma de la sostenibilidad, por lo que ésta se concibe como un espacio de realización del desarrollo humano" (Virgen, 2014: 150). Así es reconocido que la dimensión social del desarrollo sustentable exige equidad por medio de valores y variables que involucran el concepto de desarrollo humano (CESTUR, 2012: 103).

En tal sentido, se establece un estrecho vínculo entre la sustentabilidad y la seguridad de los destinos y empresas turísticas; por lo que frecuentemente es utilizada como indicador de sustentabilidad turística (CSD, 1995; Christmann, et al., 1999; AEC, 1999; INEGI, 2000; SECTUR, 2011; GSTC, 2013), ya que la seguridad en el turismo es un argumento significativo para los turistas que buscan destinos seguros y protegidos 
(CESTUR, 2012: 189). Según Blancas -tomando como base la información de World Tourism Organization, 2004- entre los aspectos sociales del turismo sustentable se encuentra la salud y la seguridad, relacionadas estas con cuestiones básicas como aspectos sanitarios y seguridad pública local, con la correspondiente influencia sobre la población visitante (Blancas, et al., 2010).

Corrobora el Instituto Distrital de Turismo de Bogotá que la seguridad es un requisito indispensable para la competitividad y la sustentabilidad del turismo. Es un derecho de visitantes y residentes, una obligación indelegable del Estado y una de las principales responsabilidades de todos los actores involucrados en la actividad turística; es decir, prestadores de servicios turísticos, autoridades, gremios, trabajadores del sector y comunidades anfitrionas. Bajo esta perspectiva, por ejemplo, la Política Distrital de Turismo formulada por el Instituto Distrital de Turismo en el año 2008, determinó la necesidad de que este liderara el "diseño e implementación de un Plan Integral de Seguridad Turística para Bogotá (IDT, 2010).

En consecuencia, la seguridad turística garantiza "la protección de la vida, la salud, la integridad física, psicológica y económica de los visitantes, prestadores de servicios y miembros de la comunidad receptora; así la seguridad se constituirá cada vez más en el valor agregado que contribuirá a la diferenciación entre los destinos de calidad" (Grünewald, s/a: 5). Igualmente, la OMT reconoce que el éxito o el fracaso de un destino dependen de su capacidad para proporcionar a los visitantes un entorno seguro. Esto requiere de la participación activa de todos en correspondencia con las responsabilidades del destino, el cual debe garantizar que la delincuencia, los hechos de violencia, conflictos bélicos, sociales, políticos, religiosos y étnicos, así como la falta de protección pública e institucional sean asuntos debidamente atendidos (Ibídem).

De tal manera la seguridad turística debe ser comprendida "bajo un enfoque integral de cumplimiento de derechos y garantía de libertades para todas las personas, con fundamento en el disfrute del espacio turístico por parte de visitantes y residentes; en actuaciones respetuosas de la diversidad y del cumplimiento de los derechos humanos; en la prevención del delito, en la interlocución y ayuda permanente entre autoridades civiles, policía y ciudadanía; y en la responsabilidad acerca del manejo de la información" (IDT, 2010: 51-52), por lo que las situaciones de violencia constituyen un factor limitativo para la gestión de la sustentabilidad de los destinos y sus organizaciones.

Según la Organización Mundial de la Salud, la violencia es el uso intencional de la fuerza o el poder físico, de hecho o como amenaza, contra uno mismo, otra persona o un grupo o comunidad, que cause o tenga 
probabilidades de causar lesiones, muerte, daños psicológicos, trastornos del desarrollo o privaciones (OMS, 2002), en la que están implicados las víctimas -objeto de la misma- y los victimarios -sujeto de ella-; debiendo utilizarse para determinar el tipo de violencia las categorías de intencional y no intencional (Londoño, et al., 2000). En contraposición, la paz se conceptualiza como "el derecho de mujeres y hombres a la no violencia y a la justicia; por lo que forma parte de los derechos humanos universales. Su reconocimiento, respeto y protección debe involucrar la actividad de los poderes públicos y la actividad judicial (Montalbán, 2009).

En la práctica la inseguridad ciudadana generada por la violencia deriva en desconfianza, ya que una comunidad aterrorizada suele desconfiar de los desconocidos y los diferentes; la desconfianza impone patrones de comportamiento irresponsable que obstaculizan la integración comunitaria y reducen la intolerancia a lo desconocido (Moser, et al., 1997). Con la misma se relacionan acciones delincuenciales y de poder coactivo que impactan negativamente sobre el turismo, como los robos e intentos de atraco, secuestros, actos de corrupción e impunidad, narcotráfico, drogadicción, vandalismo, y delincuencia organizada en grupos, mediante los que se emplea el soborno, intimidación, fuerza y ajusticiamiento, entre otros.

A propósito el Consejo Global de Turismo Sustentable sugiere como indicador para la medición de la sustentabilidad la seguridad (A12); mediante el cual se recomienda como criterio de evaluación: El destino tiene un sistema para hacer el seguimiento, prevenir, informar al público y ofrecer respuestas frente a los riesgos vinculados a la delincuencia, la seguridad o la salud (GSTC, 2013). Además, como parte de la Sección A agrega "Demostrar una gestión sostenible del destino", y en el indicador A1 "Estrategia de un destino sostenible" recomienda como criterio de medida: El destino ha formulado y está poniendo en práctica una estrategia plurianual que se encuentra a disposición del público, es adecuada a su escala, considera temas ambientales, económicos, sociales, culturales, estéticos, de calidad y de seguridad y se ha formulado con participación pública (Ibídem).

Recomienda en el punto A12 "Seguridad y Protección” (GSTC, 2013:5) que deben implementarse: inspecciones obligatorias para la prevención de incendios, garantizar la higiene de los alimentos y la seguridad eléctrica en las instalaciones turísticas; medidas de seguridad, tales como estaciones de primeros auxilios en las playas / sitios de atracción turística; sistemas para prevenir y responder a la delincuencia; precios claros en taxis y un sistema de despacho organizado en los puntos de entrada de los visitantes; e información pública sobre seguridad y protección.

Se reconoce que el destino turístico debe disponer de un sistema para controlar, prevenir, informar y responder a la delincuencia, la seguridad y los 
riesgos para la salud; y a la vez debe tener un plan de respuesta a las crisis y emergencias, cuyos elementos clave sean comunicados a los residentes, visitantes y empresas; este debe establecer los procedimientos y proporcionar recursos y capacitación al personal, visitantes y residentes, y actualizarse regularmente (Ibídem). Precisa como parte de los Criterios Globales de Turismo Sostenible para Hoteles y Tour Operadores, Sección A “Demostrar una gestión sostenible eficaz”, indicando que las organizaciones deben implementar sistemas de gestión de la sostenibilidad, cumplir con la legislación y los reglamentos pertinentes y recibir capacitación periódica en la que se integren los temas de seguridad y salud (GSTC, 2014).

De igual forma la Asociación de Estados del Caribe /AEC/ desde la Declaración de la Zona de Turismo Sostenible del Caribe /ZTSC/ ha incorporado la seguridad como indicador para evaluar la sustentabilidad de un destino (AEC, 1999), la cual está contenida en el Manual sobre Indicadores de Sustentabilidad de la AEC y utiliza como criterio de medición el número de delitos reportados por los turistas en el destino/No. total de turistas al año. Al respecto, ha desarrollado diferentes propuestas que incorporan la seguridad en el turismo, como la contenida en el Proyecto ACS-ST-003 “Desarrollo de indicadores para la ZTSC” http://www.acsaec.org/index.php?q=es/sustainable-tourism/proyectos/desarrollo-deindicadores-para-la-zona-de-turismo-sustentable-del-cari [recuperado el 11 de julio de 2015].

La Secretaría de Turismo de México a través del Programa de Turismo Sustentable -anteriormente Agenda 21 para el Turismo Mexicanoreconoce en el tema entorno socioeconómico, subtema impacto social la seguridad (1.3) como indicador de sustentabilidad de un destino (SECTUR, 2011). Según informe de “Evaluación de desempeño de los destinos en el marco de los Convenios de Coordinación en materia de Reasignación de Recursos” queda ratificada la importancia de la seguridad como parte del desarrollo sustentable; en el mismo, las variables relacionadas con el turismo fueron clasificadas en 7 dimensiones que comprenden la sustentabilidad (2) y la seguridad (7). Las mismas sirvieron como criterio para medir el desempeño turístico a través de un índice que mide el éxito de un lugar turístico cuando los ciudadanos y las empresas están satisfechos con su comunidad y la localidad se corresponde con las expectativas de los visitantes y los inversores (CESTUR, 2012).

\section{Destinos Turísticos Seguros vs. Inseguros.}

Según Bringas, la seguridad debe considerarse como un problema con evidencias empíricas concretas en cada lugar, en el que la percepción social juega un papel importante. Esto significa que deben emprenderse acciones concretas y campañas en el plano discursivo y simbólico dirigidas a 
mitigar los efectos derivados de la ocurrencia de eventos de violencia, alertas de inseguridad y percepción sobre demoras y contratiempos durante la estancia de los visitantes en el destino turístico. Reconoce que los turistas poseen características diversas que conllevan a percibir de forma diferenciada los riesgos y problemas a que pueden estar expuestos, y a su vez que generan dificultades distintas para la seguridad pública de los destinos visitados (Bringas, et al., 2008).

Entre las características de los Destinos Turísticos Seguros deben ser consideradas (Grünewald, s/a:15) las responsabilidades definidas y asumidas por el sector público por área de competencia y el sector privado por actividad; la comunicación a los interesados de las responsabilidades según ámbitos de competencia; y la adopción y cumplimiento de estándares de seguridad y prácticas en instalaciones y lugares turísticos en lo relativo a la prevención de incendios, salubridad de los alimentos, otros requisitos de seguridad sanitaria del destino, estándares ambientales, prevención de intromisiones ilegales (terrorismo), así como otros estándares y prácticas relevantes a nivel del destino turístico.

Las características de un Destino Turístico Seguro de acuerdo con Biosca (2013) se enmarcan en los 10 aspectos que componen la seguridad del sitio de visitación, los cuales corresponden a la seguridad antirrobo; sanitaria; ecológica; arquitectónica; actuación de los agentes de la autoridad; buen confort de los establecimientos de alojamiento y de los medios de transporte; nivel de los precios fiable, sin abusos en el cambio de moneda, en los comercios y mercadillos y en las tarifas de las taxis; el rol del visitante como peatón o conductor; oferta fiable; y la gastronomía que garantice la calidad de los alimentos (Biosca, 2013).

Al respecto, la Universidad Nacional de Quilmes en el marco del "Convenio Marco de Cooperación con la Organización de los Estados Americanos y la Fundación Turismo” ha desarrollado un Sistema Integral de Seguridad para Destinos y Empresas Turísticas -SISDyET-. Sus objetivos son desarrollar el concepto de seguridad turística desde una perspectiva global; establecer conceptos, analizar tendencias y experiencias sobre seguridad turística; considerar el sistema como un instrumento de gestión empresarial de desarrollo y competitividad de destinos; promover acciones de información, prevención, concientización y educación sobre la seguridad en destinos y empresas turísticas; concientizar a los prestadores de servicios y comunidades receptoras en que la seguridad es una responsabilidad de todos; y capacitar a las fuerzas de seguridad para incorporarse a la actividad como informador y promotor turístico (UNQ, 2012).

Opuestamente, las características de un Destino Turístico Inseguro impactan negativamente sobre la imagen del destino y la demanda en los mercados potenciales; entre las principales causas que inciden en que un 
destino sea inseguro se consideran factores tales como falta de normatividad relativa a la seguridad y salubridad; ineficiencia policial y las instituciones de poder; publicidad amarillista con respecto a la situación del destino; narcotráfico; y vandalismo. Estos estados de inseguridad requieren consecuentemente de estrategias que permitan el desarrollo del turismo en condiciones de mayor seguridad y paz para todos los actores implicados, propiciando de esta manera el pleno conocimiento, contribución cultural, y disfrute de los espacios puestos en valor de uso turístico.

En opinión de Cedeño (2013) y basado en el caso de la Ciudad de Caracas, los principales factores de riesgo que determinan la inseguridad en áreas metropolitanas -sobre todo en las capitales latinoamericanas y grandes ciudades- están condicionados por la alta densidad demográfica que ofrece múltiples oportunidades y víctimas para los delincuentes, a su vez que mayores retos para el control policial; presencia de espacios públicos en mal estado de conservación y en situaciones de abandono; poca iluminación; urbanización espontánea; congestionamiento vehicular y déficit policial; accesibilidad a las armas de fuego; enfrentamientos entre bandas y ajustes de cuentas; impunidad; así como leyes y políticas públicas con buenas intenciones, pero con pocas voluntades (Cedeño, 2013).

Cabe señalar que entre los factores de mayor impacto sobre la apreciación de los destinos turísticos inseguros se encuentra la propia percepción de los habitantes locales, la cual es trasmitida al visitante, así como las alertas exageradas que realizan algunos países a sus ciudadanos (Department of State, 2015a), lo que deteriora aún más la imagen turística. En este sentido es oportuno destacar que la página oficial del Departamento de Estado de Estados Unidos indica que los países en América Latina con mayor riesgo para los ciudadanos estadounidenses son México y Colombia (Department of State, 2015b), razón por la que muchos deciden no viajar a estos territorios.

En particular, el Departamento de Estado de Estados Unidos advierte a sus ciudadanos sobre los riesgos de viajar a ciertos destinos de México debido a las amenazas que representan los grupos delictivos organizados. Referido al Estado de Chihuahua, recomienda tener precaución en áreas de distritos de negocios y compras en Ciudad Juárez y sus principales parques industriales; la zona central y parques industriales de Chihuahua Capital; Nuevo Casas Grandes y Casas Grandes. Sugiere no visitar otras áreas del estado y viajar entre ciudades sólo por las principales autopistas y durante el día. Declara que el crimen y la violencia siguen siendo problemas graves en Chihuahua, sobre todo en la parte sur del estado y en la sierra, incluyendo el importante destino turístico de las Barrancas del Cobre (Department of State, 2015b). 
Con relación a la enunciación anterior cabe mencionar que el 95\% de los propios mexicanos cree que el país no es seguro, el $44 \%$ cree que el gobierno no puede garantizar la integridad de los turistas, pero a pesar de ello, siete de cada diez ciudadanos recomendaría a México como destino vacacional (Parametría, 2013). Relativo a la capacidad del gobierno para garantizar la seguridad de los turistas el $45 \%$ piensa que México tiene la capacidad de proteger a los visitantes, en oposición al 44\% que considera lo contrario; por otra parte, de residir en otro país siete de cada diez recomendarían viajar a los destinos turísticos mexicanos, en tanto el $26 \%$ lo haría solo cuando se resuelvan los problemas de inseguridad en el país (Ibídem).

\section{Gestión de riesgos y crisis en el turismo dentro del contexto de la sustentabilidad.}

El problema de la gestión integrada de riesgos y crisis en el turismo es un tema de reciente incorporación al debate científico internacional, y por tanto a la gestión práctica, por lo que se requiere del desarrollo conceptual y procedimental para ganar en eficiencia y operatividad. En opinión de Rodríguez-Toubes Muñiz y Fraiz Brea, cuando se presenta una situación de crisis en el turismo los conocimientos adquiridos sobre el tema pueden ser aprovechados como oportunidad por parte de las organizaciones y negocios turísticos, al tiempo que se convierten en reto para la competitividad y sustentabilidad, lo cual requiere de una preparación anticipada y planificación oportuna para minimizar efectos negativos (Rodríguez-Toubes, et al., 2010), así como de un sólido sistema de evaluación durante las diferentes etapas de gestión.

Al respecto, el Consejo Global de Turismo Sustentable sugiere como indicador para la medición de la sustentabilidad la gestión de situaciones de crisis y de emergencias en los destinos turísticos y sus organizaciones (A13). Propone como criterio de evaluación: El destino tiene un plan apropiado de respuesta en casos de crisis y emergencias. Los elementos más importantes se comunican a los residentes, los visitantes y las empresas. El plan establece procedimientos y proporciona recursos y formación para el personal, los visitantes y los residentes, actualizándose con regularidad (GSTC, 2013).

El Consejo Global de Turismo Sustentable recomienda que para el logro de tales fines se requiere (GSTC, 2013:5): disponibilidad pública del plan de respuesta ante crisis y emergencias en el sector turístico; capital humano y financiero para implementar el plan de respuesta ante crisis y emergencias; desarrollo del plan de actuación ante crisis y emergencias con la participación del sector público, incluyendo procedimientos de comunicación durante y después de la emergencia; plan de gestión de crisis y 
emergencias que provea recursos y capacitación para el personal, los visitantes y residentes; y plan actualizado regularmente de respuesta ante emergencias.

En la práctica internacional existen valiosas experiencias para la gestión integrada de riesgos y crisis que cubren las necesidades del turismo. Así por ejemplo, pueden mencionarse los "Proyectos de Reducción del Riesgo de Desastres” desarrollados y/o en desarrollo por parte de la Asociación de Estados del Caribe, los cuales están relacionados con temas tales como manejo de desastres, sistemas de alertas, fondo regional y mecanismos financieros post desastre, hospitales seguros, riesgo urbano, respuesta verde, reducción de riesgos y desastres, entre otros http://www.acsaec.org/index.php?q=es/reduccion-del-riesgo-de-desastres/proyectos [recuperado el 11 de julio de 2015].

\section{Metodología de estudio.}

Corresponde a una investigación aplicada en la que se utiliza el enfoque deductivo. La metodología está orientada a la solución práctica de la gestión estratégica de riesgos y crisis en el turismo generados por situaciones de inseguridad; es de carácter cualitativa, transversal y propositiva con enfoque multidisciplinar. Fueron utilizados métodos empíricos para el registro, medición cualitativa, análisis, e interpretación de la realidad, tales como la observación, análisis de documentos, estudio de casos y trabajo con grupos de población; así como métodos teóricos para la comprensión de la teoría científica, identificación de regularidades y características esenciales del fenómeno objeto de estudio, como el analítico-sintético, inductivodeductivo, histórico-lógico, y sistémico-estructural. En correspondencia con los métodos seleccionados fueron utilizadas técnicas conceptuales, descriptivas y proyectivas.

En la etapa 1 del estudio se construyeron y justificaron las bases teóricas y prácticas para la gestión integrada de riesgos y crisis en el turismo mexicano y latinoamericano como problema estratégico. Con respecto a esta se realizó la caracterización del espacio latinoamericano como contexto de estudio según fuentes documentales y se realizó una sistematización orientada a valorar el marco institucional e instrumental para la gestión de riesgos y crisis en el turismo, reconociendo las oportunidades para la gestión de eventos generados por la inseguridad.

En la etapa 2 se estudiaron las situaciones de crisis y estrategias de gestión en destinos turísticos inseguros de México y Latinoamérica utilizando información secundaria. Se basó en la interpretación de casos de destinos inseguros de México y Latinoamérica, en los que se han reportado eventos de crisis, y consecuentemente se han implementado estrategias de gestión con diferentes niveles de éxito. Esto con el propósito de establecer 
aproximaciones comparativas entre países seleccionados de la región con el fin de analizar problemáticas comunes y extraer experiencias de aprendizaje que sirvan de base a la identificación de regularidades.

Fueron seleccionados como casos de estudio diferentes destinos turísticos locales de México, Brasil, Venezuela, Colombia, Honduras, y Guatemala. El criterio de selección se fundamentó en los niveles de violencia e inseguridad reportados en diferentes momentos históricos de su ciclo de vida, así como la importancia concedida al desarrollo del turismo. Este escenario comparado pretendió comprender aspectos relativos a la situación de inseguridad experimentada a nivel del destino, conocer la capacidad de respuesta ante la crisis reportada, y la gestión turística/no turística implementada para contribuir a la minimización de los efectos adversos a que ha estado expuesto el turismo.

En la etapa 3 se conformó la proyección estratégica sustentable para la mejor preparación y planificación del turismo en Ciudad Juárez ante riesgos y eventos de crisis provocados por la inseguridad; en función de ello se trabajó con 3 grupos de discusión. En un primer momento se realizó la caracterización de Ciudad Juárez como espacio de turismo fronterizo en un contexto de inseguridad y se definió de forma participativa el problema estratégico relativo a la gestión de riesgos y eventos de crisis en el turismo a causa de la inseguridad en el destino.

De igual forma se elaboraron los principios estratégicos para conformar un Sistema de Turismo Seguro en Ciudad Juárez. El proceso de construcción se basó en los resultados del trabajo en grupos; en una primera sesión se presentaron los hallazgos y experiencias de México y América Latina (según casos seleccionados), posteriormente se realizó una jornada de elaboración, socialización y debate de la información listada por cada grupo de trabajo, la cual fue sometida a un proceso de reducción por exclusión e integración de ideas, así como de ponderación según niveles de importancia con el propósito de obtener un único sistema de principios.

Atendiendo a los resultados anteriores se identificaron los ámbitos de actuación y requerimientos mínimos para la gestión sustentable de riesgos y crisis en el turismo de Ciudad Juárez. La identificación de los requerimientos mínimos de actuación para la gestión de riesgos y crisis provocados por situaciones de inseguridad se realizó a partir de la propuesta de un documento base que fue debatido con los participantes en cada grupo de discusión. La lista fue ajustada, enriquecida y validada por los participantes. Seguidamente se realizó en sesión plenaria la evaluación de cada requerimiento atendiendo a la brecha percibida para su implementación; se utilizó una escala Likert en la que el valor 1 significa la mínima puntuación y el 10 la máxima. 
Gestión integrada de riesgos y crisis en el turismo mexicano y latinoamericano como problema estratégico para la seguridad de los destinos. Una justificación necesaria.

Breve reflexión sobre el contexto latinoamericano de paz y turismo.

Según reporte del Instituto para la Economía y la Paz, el mundo ha demostrado ser menos pacífico entre 2008 y 2015 (IEP, 2015a: 46). El impacto económico de la violencia sobre la economía mundial en 2014 ha sido estimado en 14,3 billones de dólares, lo que representa el 13,4 \% del PIB mundial. Desde 2008 el impacto económico total en el PIB mundial se ha incrementado en un 15,3 \% (IEP, 2015a: 5). Estas regularidades son inherentes a todos los países de América Latina, especialmente México.

El espacio geográfico latinoamericano está caracterizado por marcadas brechas sociales y condiciones de inequidad e inestabilidad política; a pesar de ello, se advierte un escenario único de oportunidades sociopolíticas y económicas que permiten pronosticar mejoras (Calderón, 2011). La CEPAL ha proyectado una tasa de crecimiento económico cercana a cero para América del Sur, mientras que en Centroamérica y México alcanzaría 3,2 \% y en el Caribe 1,9 \%; los países líderes en la expansión serían Panamá (PIB de 6,0\%), Antigua y Barbuda (5,4\%) y Bolivia, Nicaragua y República Dominicana (5,0\%) (CEPAL, 2015a).

De acuerdo al reporte del Instituto para la Economía y la Paz el estado de paz es bajo en México, Colombia y Venezuela; medio en Brasil, Ecuador, Perú, Bolivia y Paraguay; y alto en Chile, Argentina, y Uruguay (IEP, 2015a: 10). No obstante, de acuerdo con el referido documento (IEP, 2015a) y comentado por el Instituto Mexicano para la Competitividad (http://imco.org.mx/seguridad/indice-de-paz-mexico-2015-via-el-institutopara-la-economia-y-la-paz/ [Recuperado el 02 de julio de 2015], México ha experimentado un descenso considerable en la violencia desde 2011 y el nivel de paz a nivel nacional ha mejorado en un 16\%, con una puntuación que fluctúa entre 1,60 en Hidalgo y 3,66 en Guerrero; en este ranking el Estado de Chihuahua tiene una calificación de 2,696, lo que lo sitúa en la posición 26 en un total de 32 estados.

En opinión de J. Ganzo y colegas, en México “desde el inicio del presente sexenio se han incrementado las situaciones de riesgo, inseguridad y peligro, afectando severamente al turismo; esto se refleja en la baja afluencia turística y comercial provocada desde 2008 por las magnificadas alertas que emite Estados Unidos y por las olas de inseguridad...” ( $\underline{E n}$ : Grünewald, s/a: 79). Al respecto, proponen una estrategia compuesta por cuatro puntos principales; estos son, la desregulación de trámites para incentivar la inversión; incremento de créditos al sector; mejoramiento de la infraestructura carretera y portuaria; y facilitación de los trámites para las llegadas internacionales ( $\underline{E n}$ : Grünewald, s/a: 85). 
La puntuación global para América del Sur según el Índice de Paz de 2015 comparado con 2014 descendió ligeramente por debajo de la media mundial. La paz en Centroamérica y el Caribe logró mejorar ligeramente en comparación con igual periodo, aunque se mantiene por debajo de la media mundial y continúa siendo la región más baja del ranking mundial en términos de las tasas de homicidios y delitos violentos, así como en la percepción de criminalidad, fenómenos frecuentemente relacionados con pandillas urbanas y la delincuencia asociada a las drogas. México continúa reportando la puntuación más baja entre los países Centroamericanos y del Caribe (IEP, 2015a).

En este contexto el turismo se inserta como una importante fuente de ingresos económicos y bienestar para América Latina, llegando a representar en algunos de los países más del 30\% del PIB, y alrededor del 50\% de las exportaciones de bienes y servicios corresponde a "exportaciones" por concepto de turismo; este es el caso de las naciones del Caribe donde el sector supera el 16\%, encabezando el ranking de participación en el turismo receptor Sta. Lucía (31\%), Bahamas, y Antigua y Barbuda (CEPAL, 2011). En Centroamérica estos indicadores reflejan una participación en el consumo turístico receptor cercana al $10 \%$ del PIB -2009- y representa aproximadamente el $20 \%$ de las exportaciones de bienes y servicios; no obstante, para el conjunto de América Latina y el Caribe los ingresos por turismo representaron tan solo el 1,8\% de su PIB en el período 1980-2008, destacando algunos países como Uruguay con valor cercano al 4\% (Ibídem).

Durante el 2014 la región de Las Américas recibió un total a 182 millones de visitantes y ocupó la mejor posición en términos relativos a nivel internacional al registrar un crecimiento del 8\%, con la participación positiva de América del Norte (9\%), el Caribe (7\%), América Central (6\%) y América del Sur (5\%). Los ingresos por concepto de turismo internacional crecieron en solo 3\%, con la participación positiva de América Central (8\%), el Caribe (7\%), América del Sur (6\%), y América del Norte (2\%). Para 2015 las perspectivas pronosticadas fueron más favorables, ya que se esperaba un crecimiento de entre $4 \%$ y $5 \%$, mientras que las previsiones a largo plazo estiman una desaceleración comparativa en la llegada de turistas a la región, con un estimado de 248 millones para 2030 (UNWTO, 2015).

\section{Marco institucional e instrumental para la gestión de riesgos y crisis en el turismo. En búsqueda de oportunidades para la gestión de eventos generados por la inseguridad.}

En diferentes ámbitos de gestión se han venido gestando, y progresivamente consolidando, un conjunto de instrumentos que favorecen la atención a los riesgos y crisis en el turismo. Entre estos se encuentran el Programa Regional para Las Américas de la OMT, Programa de Desarrollo 
Sustentable del Turismo de la OMT, Programa de Gestión de Riesgos y Crisis de la OMT, Red de Respuesta ante Emergencias Turísticas, Herramientas de comunicación de crisis en el ámbito del turismo de la OMT, Sistemas de Gestión de Crisis, Reglamento Sanitario Internacional de la OMS, así como instrumentos desarrollados por la CEPAL y la Asociación de Estados del Caribe, entre otros. Cada uno de ellos aporta valiosa información al proceso de gestión de riesgos y crisis en el turismo a nivel global, regional y local, así como a sus organizaciones.

El Programa Regional para Las Américas de la OMT tiene como misión el reforzamiento de la calidad y la eficacia de la cooperación para el desarrollo a largo plazo, en correspondencia con lo cual promueve seminarios, conferencias y talleres, a la vez que asiste a los gobiernos en la obtención de conocimientos técnicos que le permitan formular políticas turísticas y estrategias para la planificación turística basada en los principios de la sustentabilidad. Desarrolla misiones de apoyo sectorial a corto plazo bajo demanda con el fin de identificar y evaluar las necesidades específicas de asistencia técnica, además de proveer asesoramiento en políticas turísticas http://americas.unwto.org/es [recuperado el 27 de junio de 2015]. Enfatiza la cooperación para el desarrollo del turismo entre los países de la región, la formación, asesoramiento y asistencia técnica con el fin de garantizar la sustentabilidad y la gestión de riesgos y eventos de crisis en el turismo regional.

Este programa desarrolló diversas actividades en el año 2014, las cuales estuvieron centradas en la promoción del desarrollo del turismo sustentable (dentro de cuyo programa se da seguimiento a riesgos y crisis en el turismo) y la cooperación regional. Así, en El Foro de Cartagena de Indias, Colombia, se abordaron temas de interés regional como la competitividad, el uso de las tecnologías en la comunicación y el desarrollo comunitario en el marco del desarrollo del turismo sustentable. Al mismo tiempo, se ha venido reforzado la cooperación con las organizaciones regionales a través de Memorandos de Entendimiento con la Organización de Turismo del Caribe (CTO) y con la Asociación de Estados del Caribe (AEC) con el fin de consolidar esfuerzos en la promoción del turismo y la sustentabilidad de la región (UNWTO, 2015).

En particular la OMT a través del Programa de Desarrollo Sustentable del Turismo ayuda a evaluar y mitigar los riesgos para el turismo, y promueve el desarrollo, planificación e implementación de sistemas de gestión de crisis que permitan reducir el impacto y ayudar en la recuperación http://rcm.unwto.org/en/content/about-us-7 [recuperado el 27 de junio de 2015]. Este enfoque permite relacionar en una cadena los conceptos de Riesgos - Eventos de Crisis - Impacto - Recuperación como base analística para la comprensión del proceso de gestión preventiva y 
correctiva de estos, al tiempo que pude relacionarse con las etapas del modelo de las 4 "Rs"; es decir, reducción y preparación pre crisis, respuesta durante la crisis y recuperación post crisis (Wilks y Moore, 2003; Rodríguez-Toubes, 2011; Pennington-Gray, 2011).

Seguidamente se presenta en síntesis el estudio de sistematización realizado con el fin de identificar áreas de oportunidad para México y los países latinoamericanos según experiencias desarrolladas por la OMT a través de diferentes proyectos y actividades (Tabla 1). De la misma se pueden inferir la necesidad de disponer de políticas y estructuras de gestión; información confiable y suficiente como base para los procesos de toma de decisiones; planificación integrada y sistémica; el desarrollo de capacidades de gestión a través de la capacitación, formación, entrenamiento y aprendizaje de experiencias previas; y disponibilidad de recursos humanos, materiales y financieros para la actuación directa durante todas las etapas del ciclo de vida de una crisis en el turismo.

Tabla 1 Áreas de oportunidad para México y los países latinoamericanos derivados de experiencias desarrolladas por la OMT a través de diferentes proyectos y actividades.

\begin{tabular}{|c|c|c|}
\hline Proyectos / actividades & Actuación de la OMT & Áreas de oportunidades \\
\hline $\begin{array}{l}\text { Movimiento seguro y } \\
\text { eficiente de los viajes } \\
\text { internacionales a través } \\
\text { de medidas para facilitar } \\
\text { los desplazamientos } \\
\text { internacionales. }\end{array}$ & $\begin{array}{l}\text { Desarrolla normas, procedimientos e } \\
\text { información para sortear amenazas, } \\
\text { reducir costos y ayudar el movimiento } \\
\text { seguro, saludable y eficiente de viajeros. } \\
\text { Ofrece información y advertencias de } \\
\text { viajes. Coordina con la OMS en el } \\
\text { marco del Reglamento Sanitario } \\
\text { Internacional (RSI). }\end{array}$ & $\begin{array}{c}\text { Planificación. } \\
\text { Información. } \\
\text { Advertencias de viajes. } \\
\text { Coordinación con la OMS para viajes } \\
\text { seguros. }\end{array}$ \\
\hline $\begin{array}{l}\text { 2. Identificación y } \\
\text { mitigación de riesgos } \\
\text { globales y locales } \\
\text { relacionadas con el } \\
\text { turismo. }\end{array}$ & $\begin{array}{l}\text { Apoya esfuerzos de gestión de crisis en } \\
\text { el turismo a nivel nacional, centrándose } \\
\text { en el establecimiento de Sistemas } \\
\text { eficaces de Gestión de Crisis (CMS) y la } \\
\text { mejora de estos, identifica estructuras y } \\
\text { procedimientos de emergencia } \\
\text { nacionales. Prepara directrices y casos } \\
\text { de buenas prácticas, proporciona } \\
\text { estrategias de mitigación, acciones e } \\
\text { instrumentos para evaluar riesgos a } \\
\text { través de talleres de capacitación sobre: } \\
\text { Planificación de Emergencias en el } \\
\text { Turismo; Análisis de Riesgos en el } \\
\text { Turismo, Atención Temprana y } \\
\text { Cartografía; Coordinación de Crisis a } \\
\text { nivel Nacional e Internacional; } \\
\text { Comunicación de Crisis; y Técnicas de } \\
\text { Recuperación. }\end{array}$ & $\begin{array}{c}\text { Identificación / mitigación de riesgos. } \\
\text { Elaboración de Sistemas de Gestión de } \\
\text { Crisis. } \\
\text { Apoyo de esfuerzos a la gestión de } \\
\text { crisis. } \\
\text { Identificación de estructuras y } \\
\text { procedimientos de gestión. } \\
\text { Sistematización de buenas prácticas de } \\
\text { gestión. } \\
\text { Estrategias de mitigación. } \\
\text { Acciones e instrumentos para la } \\
\text { evaluación de riesgos. } \\
\text { Entrenamiento y capacitación. }\end{array}$ \\
\hline $\begin{array}{l}\text { 3. Coordinación con el } \\
\text { sistema de las Naciones } \\
\text { Unidas para permitir y } \\
\text { garantizar un enfoque } \\
\text { de trabajo coherente y } \\
\text { común. }\end{array}$ & $\begin{array}{l}\text { Promueve, coordina y coopera para la } \\
\text { preparación y actuación en áreas de } \\
\text { salud, seguridad, delincuencia, desastres } \\
\text { naturales / antrópicos, y otras, con } \\
\text { organizaciones y estrategias de la OMS } \\
\text { (brote de la pandemia -H1N1- en 2009), } \\
\text { Estrategia Internacional para la } \\
\text { Reducción de Desastres (EIRD), } \\
\text { Federación Internacional de Sociedades } \\
\text { de la Cruz Roja y de la Media Luna } \\
\text { Roja (FICR), Organización de la } \\
\end{array}$ & $\begin{array}{c}\text { Coordinación y cooperación inter } \\
\text { institucional con el sistema de las } \\
\text { Naciones Unidas para la gestión de } \\
\text { crisis. } \\
\text { Estrategias de gestión de crisis y } \\
\text { reducción de riesgos y desastres. }\end{array}$ \\
\hline
\end{tabular}




\begin{tabular}{|c|c|c|}
\hline & $\begin{array}{c}\text { Aviación Civil Internacional (OACI), } \\
\text { Instituto Internacional de } \\
\text { Investigaciones de las Naciones Unidas } \\
\text { sobre Crimen y Justicia (UNICRI); } \\
\text { Oficina de las Naciones Unidas para la } \\
\text { Reducción del Riesgo de Desastre } \\
\text { (UNISDR), y el Programa de las } \\
\text { Naciones Unidas para el Desarrollo } \\
\text { (PNUD). }\end{array}$ & \\
\hline $\begin{array}{l}\text { Fomento de capacidades } \\
\text { para desarrollar, } \\
\text { planificar y poner en } \\
\text { práctica Sistemas de } \\
\text { Gestión de Crisis en el } \\
\text { turismo. }\end{array}$ & $\begin{array}{l}\text { Desarrolla talleres según necesidades } \\
\text { regionales y nacionales que abordan el } \\
\text { enfoque sistemático para la gestión de } \\
\text { riesgos y crisis, incluyendo estructuras } \\
\text { de organización, responsabilidades, } \\
\text { políticas y procedimientos; } \\
\text { planificación de emergencias en el } \\
\text { turismo; prevención de desastres en } \\
\text { áreas de desarrollos turísticos; } \\
\text { coordinación en tiempos de crisis, } \\
\text { incluyendo el establecimiento de } \\
\text { prioridades, el mantenimiento de la red } \\
\text { y la coordinación; centros de } \\
\text { operaciones de crisis; procedimientos y } \\
\text { técnicas; comunicación de crisis; } \\
\text { desarrollo de productos turísticos en } \\
\text { entornos difíciles; y estrategias e } \\
\text { instrumentos para la recuperación de } \\
\text { destinos turísticos. }\end{array}$ & $\begin{array}{c}\text { Capacitación y formación. } \\
\text { Desarrollo de capacidades } \\
\text { institucionales. } \\
\text { Aplicación del enfoque sistémico a la } \\
\text { gestión de riesgos y crisis en el } \\
\text { turismo. } \\
\text { Promoción de estructuras, políticas, } \\
\text { responsabilidades, instrumentos, } \\
\text { procedimientos y planes para la } \\
\text { prevención, gestión de riesgos y crisis, } \\
\text { comunicación y recuperación de } \\
\text { destinos. } \\
\text { Coordinación en tiempos de crisis. } \\
\text { Identificación de prioridades. } \\
\text { Desarrollo de redes de trabajo. } \\
\text { Centros de operación de crisis. }\end{array}$ \\
\hline $\begin{array}{l}\text { 5lanificación e } \\
\text { implementación de } \\
\text { esfuerzos para asegurar } \\
\text { enfoques comunes a } \\
\text { nivel internacional, } \\
\text { especialmente a través } \\
\text { de ejercicios de } \\
\text { simulación } \\
\end{array}$ & $\begin{array}{l}\text { Coordina la preparación a través de } \\
\text { ejercicios de simulación generalmente a } \\
\text { niveles regionales y enfocados a la salud } \\
\text { y otras amenazas específicas para el } \\
\text { turismo, con el fin de entrenar las } \\
\text { habilidades de respuesta e identificar las } \\
\text { posibles áreas de mejora. }\end{array}$ & $\begin{array}{c}\text { Coordinación/planificación. } \\
\text { Desarrollo de habilidades en respuesta } \\
\text { a eventos de crisis. } \\
\text { Identificación de áreas de mejora para } \\
\text { la minimización de riesgos e impactos. } \\
\text { Simulación de eventos de crisis en el } \\
\text { turismo. }\end{array}$ \\
\hline $\begin{array}{l}\text { Asistencia de } \\
\text { emergencia a los } \\
\text { estados miembros } \\
\text { durante eventos de } \\
\text { crisis. }\end{array}$ & $\begin{array}{c}\text { Ofrece asistencia directa a esfuerzos de } \\
\text { gestión de crisis en el turismo a nivel } \\
\text { nacional durante la etapa de crisis o fase } \\
\text { de recuperación a petición del estado } \\
\text { miembro. }\end{array}$ & $\begin{array}{l}\text { Asistencia y apoyo directo en } \\
\text { emergencias en las etapas de crisis y } \\
\text { recuperación post crisis. }\end{array}$ \\
\hline $\begin{array}{l}\text { 7. Coordinación a través } \\
\text { del Programa de } \\
\text { Desarrollo Sustentable } \\
\text { del Turismo para la } \\
\text { actuación en situaciones } \\
\text { de crisis. }\end{array}$ & $\begin{array}{l}\text { Coordina esfuerzos, información y } \\
\text { mensajes durante las crisis } \\
\text { internacionales que tienen un impacto } \\
\text { importante en el sector. } \\
\text { Desarrolla acciones directas a través de } \\
\text { la Red de Respuesta ante Emergencias } \\
\text { Turísticas (TERN). }\end{array}$ & $\begin{array}{c}\text { Coordinación y apoyo. } \\
\text { Información y comunicación para la } \\
\text { actuación en tiempos de crisis en el } \\
\text { turismo. } \\
\text { Activación de la Red de Respuesta } \\
\text { ante Emergencias Turísticas (TERN) } \\
\text { en caso de crisis. }\end{array}$ \\
\hline
\end{tabular}

Fuente: Elaboración propia basada en información publicada por la OMT, disponible en http://rcm.unwto.org/en/content/about-us-7 [recuperado el 27 de junio de 2015].

Según información sistematizada se revela la importancia de prestar atención a los tres componentes críticos de la gestión de eventos de crisis en el turismo, conocidos como las 3 “C”: comunicación, coordinación y colaboración. El Sistema de Gestión de Crisis CC-CMS reconoce que la comunicación facilita mensajes de notificación de emergencias; la coordinación proporciona respuesta, conexión y registro de eventos entre los niveles de gestión, los individuos y/o departamentos de la organización, por 
lo que los gerentes de contingencia pueden gestionar y colaborar con los equipos de respuesta a las crisis y promover la recuperación del negocio; la colaboración asegura que todos sean conscientes de su responsabilidad, tomen decisiones informadas, coordinadas, e inmediatas para la rápida solución, apoyados en información confiable, colaboración fluida y la reducción de costos http://www.crisiscommander.com/incident-management/ [recuperado el 01 de julio de 2015].

La Red de Respuesta ante Emergencias Turísticas (TERN) trabaja con el Sistema de las Naciones Unidas y la OMT para promover la colaboración y cooperación entre los decisores y el turismo en respuesta a acontecimientos imprevistos e imprevisibles de carácter perjudicial. Contribuye a hacer los viajes y destinos seguros, compartiendo información, mensajes públicos claros, concisos y geográficamente específicos; se activa en emergencias regionales y globales de relevancia o si lo solicitara un miembro. Colaboran con TERN en la región la Asociación Americana de Hoteles y Alojamientos; Asociación Latinoamericana y del Caribe de Transporte Aéreo; Sociedad Americana de AAVV; Asociación de Hoteles y Turismo del Caribe; y Organización de Turismo del Caribe http://rcm.unwto.org/en/content/about-tourism-emergency-responsenetwork-tern-0 [recuperado el 27 de junio de 2015].

Las Herramientas de Comunicación de Crisis en el ámbito del Turismo de la OMT se basan en que los procesos de comunicación de crisis son un componente básico para la gestión de destinos y sus entidades, por lo que ofrece a las Organizaciones Nacionales de Turismo, a las Organizaciones de Gestión de Destinos y al Sector Privado una guía práctica que integra instrumentos útiles para la implementación ante los desafíos que representan los eventos de crisis para el desarrollo del turismo. Estos son protocolos detallados de actuación, listas de verificación, plantillas de muestra configuradas por tipo de crisis y categoría mediática, directrices para medir la eficacia, prácticas recomendadas y el uso de los medios sociales en situaciones de crisis (OMT, 2012).

Existen diversos productos disponibles para la gestión de crisis, algunos de ellos innecesariamente complejos y difíciles de usar y mantener, lo que se complica aún más cuando no existe un equipo dedicado, el tiempo y los recursos suficientes; otros casos son más amigables como el Sistema de Gestión de Crisis CC-CMS que tiene una interfaz intuitiva y navegación lógica que simplifica el proceso de aprendizaje, haciendo posible la ejecución de ejercicios y simulacros para validar el sistema y su implementación http://www.crisiscommander.com/incident-management/ [recuperado el 01 de julio de 2015].

El Reglamento Sanitario Internacional de la OMS es un acuerdo jurídicamente vinculante que pretende prevenir la propagación de 
enfermedades a través de los viajes con el fin de garantizar la seguridad en salud pública mediante la detección, evaluación, notificación y respuesta a las amenazas de emergencia, las cuales pueden ser consecuencia de infecciones emergentes como el Síndrome Respiratorio Agudo Severo (SARS) o una nueva pandemia de gripe humana, por lo que contribuye a la prevención de su propagación. Es importante ya que reduce los impactos negativos sobre el sector y los pasajeros; controla la propagación de enfermedades transmisibles y de acciones de respuesta rápida; a la vez que limita las restricciones innecesarias de viajes http://rcm.unwto.org/es/node/23089 [recuperado el 27 de junio de 2015].

La Comisión Económica para América Latina y el Caribe brinda apoyo técnico en evaluación de desastres y vulnerabilidad. Ha desarrollado una metodología para la evaluación del impacto socioeconómico y ambiental de los desastres naturales, con experiencias exitosas en respuesta ante terremotos, huracanes, y tsunamis (CEPAL, 2015b). Indica que "la alta vulnerabilidad de la subregión mesoamericana y caribeña dada por el tamaño, grado de desarrollo desigual, y la diferente capacidad para enfrentar los riesgos concretados en la creciente recurrencia de desastres, requiere cambiar los enfoques actuales de tipo reactivo/respuesta post desastres hacia un enfoque precautorio, que permita evitar la pérdida de vidas y de patrimonio, así como, de dinamismo económico junto con la incrementada degradación y pérdida de recursos naturales” (Ibídem).

El programa de trabajo en materia de evaluación de desastres de la Sede Subregional de CEPAL en México se coordina e inserta en una estrategia de alcance regional que incluye (CEPAL, 2015b):

- Conocimiento de los impactos estáticos y dinámicos de los desastres, promoviendo su estudio en centros de investigación e incorporando la temática de la reducción del riesgo en la currícula académica, y enfatizando el carácter multidisciplinario e intersectorial del riesgo.

- Capacidades nacionales para evaluar los impactos de los desastres para generar indicadores georeferenciados de riesgo (adicional a los mapas de amenazas o indicadores de vulnerabilidad).

- Tendencias de variación y cambio climático que se concretan en desastres, y su evaluación para aportar elementos a la cuantificación de los recursos necesarios, tanto para la reducción del riesgo ante desastres de alta recurrencia, como para la adaptación a las condiciones cambiantes que se asocian al cambio climático y al estado de degradación ambiental.

- Inserción del tema de reducción del riesgo y adaptación en las estrategias regionales y nacionales; de no hacerse se dificultan, 
retrasan o nulifican los efectos de los otros ejes estratégicos del desarrollo (productividad, competitividad y busca de equidad).

Para el caso de México la Secretaría de Turismo /SECTUR/ tiene como como misión conducir el desarrollo turístico nacional articulando las acciones de diferentes instancias y niveles de gobierno http://www.sectur.gob.mx/conoce-la-sectur/vision-y-mision/ [recuperado el 09 de junio de 2015]. El Programa Sectorial de Turismo 2013-2018 establece el Objetivo 2 "Fortalecer las ventajas competitivas de la oferta turística", en el que enuncia como Estrategia 2.5. "Impulsar una política de seguridad integral para proporcionar una experiencia turística satisfactoria y plena a los visitantes"; traza entre las líneas de acción: diseño e instrumentación de un modelo de seguridad, asistencia y protección integral turística; operativos de atención al turista; auxilio en zonas de mayor afluencia; información para crear una experiencia confiable y de calidad; y protocolos de atención para atender a turistas en contingencias.

Tomando en consideración los antecedentes sistematizados es indudable que la gestión de riesgos y crisis en el turismo mexicano y latinoamericano puede constituirse en un problema estratégico para la actuación ante cualquier evento que impacte negativamente sobre los destinos y sus organizaciones. Al respecto, será necesario considerar como indicadores básicos de gestión por lo menos los siguientes:

- Tipos de riesgos y crisis que acaparan las mayores preocupaciones para los destinos/organizaciones turísticas.

- Tipos y niveles de preparación de los destinos/organizaciones turísticas propensos al impacto de riesgos y crisis.

- Existencia en cada uno de los destinos/organizaciones turísticas de un plan de gestión de riesgos y crisis.

- Instrumentos y mecanismos de respuesta rápida de los destinos/organizaciones turísticas cuando una crisis afecta los negocios turísticos.

- Monitoreo y control sobre la eficiencia de los mecanismos de respuesta ante riesgos y crisis en el turismo.

- Sistema de acciones mediante las que se implemente la recuperación de los destinos/organizaciones turísticas en la etapa de post crisis.

La búsqueda de respuestas a estas urgentes necesidades justifica la planificación y preparación para los efectos adversos de los eventos de crisis, ya que permite conocer el fenómeno según niveles de riesgo social, ambiental y económico, reconocer las mejores prácticas de gestión en el turismo, valorar los niveles actuales de planificación y preparación del sector turístico para enfrentar riesgos y crisis, entrenarse en las etapas básicas del proceso e identificar las estructuras organizacionales y asignación de 
recursos en apoyo a la gestión de dichos eventos, así como disponer de programas de actuación para su implementación a niveles diferentes de gestión.

El enfoque estratégico que deberá implementarse ante casos de riesgos y eventos de crisis es de gran necesidad e importancia para el sector turístico regional en respuesta a los eventos catastróficos diversos que enfrenta, debido a que permite transferir los resultados a los beneficiarios (sector público en los diferentes niveles de gobierno; prestadores de servicios turísticos; comunidad local; turistas; instituciones de educación turística; etc.), quienes quedarán fortalecidos para cubrir los siguientes 4 ámbitos de actuación:

- Reducir los riesgos y crisis en el turismo: mediante políticas de observación, vigilancia, monitoreo, protocolos y procedimiento de prevención, percepciones del riesgo, etc.

- Prepararse para los riesgos y crisis en el turismo: mediante la planificación estratégica, táctica y operativa.

- Responder ante los riesgos y crisis en el turismo: fortaleciendo la capacidad de respuesta, activación de las acciones de respuesta, comunicación eficiente, y asistencia a damnificados.

- Recuperarse de los efectos de las crisis en el turismo: a través de la implementación de acciones de recuperación y seguimiento.

Los beneficios de implicar a los diferentes actores del destino/organización en las propuestas de gestión con enfoque participativo fortalecen los vínculos de acción colaborativa entre los participantes y la generación de conciencia sobre el aprovechamiento de las oportunidades de implementación de los principios del turismo sustentable, ya que les permitirá:

1. Aprender cómo el destino/organización puede prepararse mejor para eventos de riesgos y crisis que afectan el turismo y el bienestar económico general.

2. Permitir que el destino/organización pueda responder a los riesgos y crisis, y proteger a los visitantes, empleados y la imagen/marca de la empresa, su responsabilidad social, etc.

3. Acortar los tiempos de recuperación tras un evento de crisis en el turismo.

4. Integrar una red con grupos de profesionales del sector a través del aprendizaje compartido basado en la cooperación, intercambio de buenas prácticas, y la asistencia en tiempos de crisis.

5. Aprender los procesos específicos y tangibles para el desarrollo de un plan integral, detallado y viable a implementar en el destino y sus organizaciones.

6. Generar oportunidades de aprendizaje para el desarrollo de líderes 
en crecimiento dentro del sector turístico especializados en la gestión de riesgos y crisis.

7. Crear o mejorar significativamente los planes de gestión de riesgos y crisis en el turismo, lo que permitirá al destino/organización prepararse, responder y recuperarse ante eventos adversos.

8. Desarrollar una relación a largo plazo con las familias y comunidades que han experimentado sucesos trágicos en el destino/organización.

9. Asociarse con otras empresas turísticas para abordar las cuestiones de financiación, comunicación e infraestructura necesarias durante los diferentes momentos de una crisis en el turismo.

\section{Situaciones de crisis y estrategias de gestión en destinos turísticos inseguros de Latinoamérica y México.}

De acuerdo con un estudio realizado por el Consejo Ciudadano para la Seguridad Pública de México se advierte una preocupante situación para América Latina, pues 40 de las 50 ciudades más violentas se encuentran en la región (Rojas, 2012). En opinión del Presidente de la Organización, este informe permite a los gobiernos locales tomar decisiones con respecto a sus planes de seguridad y reflexionar sobre las causas de los altos índices de violencia. El informe agrega que faltan políticas públicas y presión de los medios de comunicación, así como exigencia por parte de la sociedad civil, y añade que se debe trabajar para disminuir la impunidad y consolidar la acción de fiscalías y procuradurías junto con los poderes judiciales, aunque se evidencia aún resistencia por parte de algunas autoridades para aceptar las cifras, ya que pudieran querer mostrar una realidad diferente por motivos varios, como la caída de la inversión y el turismo (Ibídem).

Atendiendo a la información elaborada por el Instituto de Economía y Paz “El Índice de Paz Global /IPG/ del 2015 en los países de Centro América, el Caribe y América del Sur” se elaboró la tabla 2 en la que se relacionan como base para el presente estudio los de mayores problemas debidos a la inseguridad y la violencia. Los mismos reflejan ser los países menos pacíficos según el IPG (IEP, 2015), reconociéndose los valores más elevados para México y Colombia. A su vez la tabla 3 lista las ciudades más violentas del mundo contenidas en los países seleccionados como casos de estudio, reflejando que el único país con 3 ciudades incluidas entre las más violentas es México. 
Tabla 2 Clasificación regional y por países (seleccionados) en el Índice de Paz Global.

\begin{tabular}{|c|c|c|c|c|c|}
\hline $\begin{array}{l}\text { REGIONES Y } \\
\text { PAÍSES }\end{array}$ & $\begin{array}{l}\text { CLASIF } \\
\text { ICA- } \\
\text { CIÓN } \\
\text { GENER } \\
\text { AL }\end{array}$ & $\begin{array}{l}\text { PUNTUA- } \\
\text { CIÓN } \\
\text { GLOBAL }\end{array}$ & $\begin{array}{l}\text { CAMBIO EN LA } \\
\text { PUNTUACIÓN/ } \\
\text { AÑO } \\
\text { ANTERIOR }\end{array}$ & $\begin{array}{l}\text { CLASIFICA } \\
\text {-CIÓN } \\
\text { REGIONAL }\end{array}$ & $\begin{array}{l}\text { COSTO DE LA } \\
\text { VIOLENCIA }\end{array}$ \\
\hline \multicolumn{6}{|c|}{ CENTRO AMERICA Y EL CARIBE } \\
\hline Honduras & 116 & 2.210 & -0.050 & $9 / 12$ & US\$ 8,357,648,685 \\
\hline Guatemala & 118 & 2.215 & -0.014 & $10 / 12$ & US\$ $11,560,741,639$ \\
\hline México & 144 & 2.530 & -0.016 & $12 / 12$ & US\$ 221,435,321,551 \\
\hline \multicolumn{2}{|c|}{ Promedio Regional } & \multicolumn{3}{|l|}{2.091} & \\
\hline \multicolumn{6}{|c|}{ SUDAMÉRICA } \\
\hline Brasil & 103 & 2.122 & -0.075 & $9 / 11$ & US\$ $254,883,857,430$ \\
\hline Venezuela & 142 & 2.493 & -0.099 & $10 / 11$ & US\$ 63,989,726,194 \\
\hline Colombia & 146 & 2.720 & +0.049 & $11 / 11$ & US\$ $113,714,606,726$ \\
\hline \multicolumn{2}{|c|}{ Promedio Regional } & \multicolumn{3}{|l|}{2.053} & \\
\hline
\end{tabular}

Fuente: Elaboración propia basado en IEP, 2015: 12.

Tabla 3 Listado de casos seleccionados entre las 50 ciudades más violentas del mundo en 2014.

\begin{tabular}{|c|c||c|c|c|c|}
\hline Posición & Ciudad & País & Homicidios & Habitantes & Tasa \\
\hline 1 & San Pedro Sula & Honduras & 1,317 & 769,025 & 171.20 \\
\hline 2 & Caracas & Venezuela & 3,797 & $3,273,863$ & 115.98 \\
\hline 3 & Acapulco & México & 883 & 847,735 & 104.16 \\
\hline 25 & Guatemala & Guatemala & 1,288 & $3,074,054$ & 41.90 \\
\hline 27 & Juárez & México & 538 & $1,347,165$ & 39.94 \\
\hline \hline 43 & Chihuahua & México & 289 & 868,145 & 33.29 \\
\hline \hline 49 & Medellín & Colombia & 657 & $2,441,123$ & 26.91 \\
\hline
\end{tabular}

Fuente: Elaboración propia basado en Forbes, 2015a.

Nótese como no existe correspondencia directa entre las ciudades más inseguras y las ciudades más visitadas por turismo internacional en América Latina (Forber, 2015b). Estas aparecen listadas en el ranking de la tabla 4, a pesar de que otros factores pueden ejercer influencia sobre el ordenamiento del mismo. Dos de los países con índices de paz bajo en la región (México y Colombia) y uno con estado de paz medio (Brasil) contienen destinos ubicados en las posiciones 2, 8, y 7 respectivamente entre las ciudades más visitados en 2015. Resalta el caso de México cuya ciudad capital sobresale por la recepción de turistas internacionales a pesar de las clasificaciones en que se ubica el país.

Tabla 4 Ciudades más visitadas de América Latina.

\begin{tabular}{|c|c|c|}
\hline Ranking & Destino & Total de visitantes \\
\hline 1 & Lima, Perú & 4.2 millones \\
\hline 2 & Ciudad de México, México & 2.82 millones \\
\hline 3 & Sao Paulo, Brasil & 2.44 millones \\
\hline 4 & Punta Cana, República Dominicana & 2.42 millones \\
\hline 5 & Buenos Aires, Argentina & 1.8 millones \\
\hline 6 & San José, Costa Rica & 1.51 millones \\
\hline 7 & Río de Janeiro, Brasil & 1.27 millones \\
\hline 8 & Bogotá, Colombia & 1.1 millones \\
\hline 9 & Montevideo, Uruguay & 860,672 \\
\hline 10 & Quito, Ecuador & 695,976 \\
\hline
\end{tabular}

Fuente: Elaboración propia basado en Forbes, 2015b. 
Tomando en consideración el estudio comparado entre 8 ciudades seleccionadas -2 mexicanas y 6 de otros países latinoamericanos-, las cuales han sido clasificadas como destinos turísticos inseguros se identifican las siguientes regularidades y tendencias que permiten comprender mejor las situaciones de crisis y estrategias de gestión en destinos turísticos de esta tipología dentro de la región.

Se aprecia que los casos estudiados corresponden a ciudades en diferentes etapas del ciclo de vida de la crisis, ya que unas se encuentran inmersas en la más profunda situación de inseguridad como San Pedro Sula, Caracas y Acapulco, en tanto otras se ubican en un proceso de recuperación progresiva de las situaciones de falta de seguridad en el turismo, con tendencia a la recuperación post crisis.

En general se han establecido diversas iniciativas -más bien aisladaspor parte de cada destino; pero no se advierte una preparación y planificación integrada para la gestión de riesgos y crisis en el turismo. Se infiere también la insuficiencia de procedimientos para la comunicación en situaciones de crisis y post crisis, tanto a nivel de destino como de sus organizaciones. Esta situación se relaciona con una limitada capacidad de respuesta ante los eventos de crisis con impactos sobre el turismo, a pesar de que se reportan en algunos de los casos seleccionados mecanismos e instrumentos de gestión de crisis que contribuyen a la minimización de los efectos adversos que pudieran generarse para el sistema turístico.

Se revela que cuando se incrementan los niveles de inseguridad en el destino disminuye la afluencia de visitantes, sobre todo internacionales, crece la incertidumbre entre los inversionistas y la falta de confianza en la población local. Consecuentemente, se deteriora la imagen turística del destino. Además, cuando hay una atención solo focalizada en la seguridad al turista se descuida la seguridad de la comunidad anfitriona y de sus propias empresas turísticas.

Como experiencias de aprendizaje derivadas del estudio de casos se establecen las siguientes regularidades, la cuales pueden ser estudiadas para su implementación en el contexto latinoamericano y especialmente en el caso de Ciudad Juárez, México:

- Viabilidad de un modelo inteligente y operativo de seguridad para los destinos turísticos, de carácter endógeno y participativo activo.

- Integración entre los diferentes niveles de gobierno para el fortalecimiento de las acciones de seguridad en los destinos turísticos.

- Necesidad de proyectar políticas integradas de gestión de la seguridad en los destinos y crear/fortalecer instituciones gubernamentales responsabilizadas y comprometidas con la planificación, intervención, asistencia, monitoreo y control, así como la coordinación interinstitucional, la colaboración y cooperación. 
- Importancia de contar con un plan integral de seguridad turística para cada destino según necesidades específicas con enfoque de sustentabilidad (sustentabilidad - seguridad).

- Necesidad de generar sistemas de información integrada, confiable, transparente, oportuna, al alcance y conocimiento de todos, tanto en el propio destino como en los lugares que se genera la demanda turística.

- Creación/actualización de bases de datos sobre la seguridad como fuente clave para los procesos de toma de decisión a nivel de destino.

- Educación de la cultura ciudadana y sensibilización para el fortalecimiento consciente de la seguridad de los destinos.

- Consejos ciudadanos para la seguridad pública y programas de acción ciudadana a favor de la promoción y control de la seguridad del destino.

- Proyectos de remodelación urbana, logística y financiamiento suficiente para la disminución de las oportunidades que condicionan la inseguridad y mejoramiento de los índices de seguridad a nivel comunitario con la participación de todos los vecinos (iluminación, pavimentación, eliminación de espacios baldíos, mecanismos de control de los conflictos urbanos, etc.).

- Creación de consejos de seguridad turística en ámbitos de la hotelería, restaurantería, corredores turísticos, etc.

- Protección al turista para evitar asaltos, secuestros y extorsiones, facilitando las oportunidades para presentar denuncias y recibir respuestas oportunas.

- Rol de las instituciones internacionales en apoyo a los programas e iniciativas a favor de la seguridad de los destinos locales.

- Importante rol de la policía turística especializada en el control de la seguridad de los destinos.

- Ubicación de cámaras de seguridad y otros equipamientos de control en zonas de mayor gravitación turística.

- Promoción del rol que pueden desempeñar las Organizaciones No Gubernamentales Internacionales a favor de la seguridad de los destinos.

Otra posible contribución a la gestión sustentable de riesgos y crisis en el turismo mexicano y latinoamericano como problema estratégico para la seguridad de los destinos pudiera ser la consolidación del Manifiesto de Bogotá para la creación de una Red Internacional de Destinos Seguros, propuesto en el marco del Primer Encuentro Internacional de Seguridad Turística: destinos competitivos y sostenibles, suscrito en Bogotá, D.C., a los 11 días del mes de noviembre de 2010 (IDT, 2010:51-52). El mismo acordó: 
1. Gestionar la creación de una Red Internacional de Destinos Seguros, que contribuya a posicionar a América Latina y El Caribe como una región integrada, turística y atractiva.

2. Enmarcar la red en una definición de seguridad turística integral, privilegiando el disfrute del espacio turístico por parte de turistas y receptores; y bajo el enfoque de respeto a los derechos y libertades que promueva la interrelación entre lo global y lo local.

3. Crear definiciones comunes en el turismo regional bajo la óptica de una actividad social con implicaciones económicas, que debe ser sostenible y estar al servicio de la paz, de manera que pueda liderar el desarrollo económico y el mejoramiento de las condiciones de vida de las comunidades receptoras.

4. Intercambiar experiencias $\boldsymbol{y}$ conocimientos para abordar las problemáticas comunes de los destinos en materia de seguridad turística, en especial la explotación sexual comercial de niñas, niños y adolescentes y la trata de personas.

5. Promover la cualificación de la policía que desarrolla funciones en las zonas turísticas, para que desempeñe sus labores, dentro del marco de los derechos y libertades de todas las personas y en consonancia con las políticas y prioridades turísticas regionales.

6. Crear un Sistema de Información de Seguridad Turística que permita el intercambio y retroalimentación en el tema y la producción de indicadores, estadísticas y estudios cualitativos.

7. Desarrollar mecanismos de coordinación con las instancias nacionales y regionales, así como esquemas de corresponsabilidad social con el sector privado.

8. Desarrollar mecanismos tendientes a democratizar los beneficios del turismo, de manera que cada vez, más personas se beneficien de la actividad y por lo tanto se hagan corresponsables de la salvaguarda de los espacios y de los bienes turísticos.

9. Consolidar mecanismos de monitoreo y evaluación, que permitan medir el impacto de las actividades que se implementen y fomentar su sostenibilidad.

10. Establecer como Secretaría Técnica permanente de la Red al Instituto Distrital de Turismo, con el apoyo de la Secretaría de Gobierno de Bogotá. 
Proyección estratégica sustentable para la mejor preparación y planificación del turismo en Ciudad Juárez ante riesgos y crisis provocadas por la inseguridad.

Ciudad Juárez como espacio de turismo fronterizo en un contexto de inseguridad.

Una de las causas principales de la violencia en diferentes estados del país está condicionada por el narcotráfico, ya que es una de las actividades que ha tenido mayor auge en México, Chihuahua y Ciudad Juárez como municipio principal. En particular Juárez está ubicada en el Estado de Chihuahua, el cual registra un Índice de Paz en México de 2.96 y ranking 26 de 32 estados (IEP, 2015a); la ciudad ocupa el lugar 27 entre las 50 ciudades más violentas contabilizadas, y el tercer lugar en México (Forbes, 2015a).

Según F. Calderón "En las últimas décadas del siglo pasado Juárez vivió un crecimiento poblacional vertiginoso...éste no vino acompañado de una inversión adecuada en servicios públicos por parte de las autoridades responsables. Cada año, decenas de miles de personas llegaban en busca de empleo, creando nuevas colonias en las que no existían servicios tan básicos como agua, luz, drenaje o pavimentación y mucho menos hospitales y clínicas, guarderías o escuelas”...no es extraño que un gran número de niños y jóvenes se hayan visto en una situación de abandono y vulnerabilidad...una sociedad donde los niños y jóvenes no cuentan con los servicios más elementales es una sociedad que no puede hacer frente a problemas tan graves como las adicciones, la violencia y el delito, y agrega que la sociedad juarense fue perdiendo el sentido de comunidad y con ello sus habitantes perdieron la capacidad de enfrentar, juntos, sus desafíos (Blog de la Presidencia, 2012).

Problema estratégico relativo a la gestión de riesgos y eventos de crisis en el turismo provocados por la inseguridad en Ciudad Juárez.

No existe un plan único y apropiado a nivel de destino turístico y sus organizaciones para la gestión de riesgos y situaciones de crisis y de emergencias, el cual sea de conocimiento de los residentes, los visitantes y las empresas; por lo que no se dispone de procedimientos, recursos suficientes y formación del personal, los visitantes y los residentes. Hasta el momento el destino no ha formulado y puesto en práctica una estrategia plurianual adecuada y a disposición del público, sobre la seguridad turística con enfoque participativo. Por tal motivo, el destino no cumple con dos importantes indicadores de sustentabilidad de los propuestos por el Consejo Global de Turismo Sustentable (Ver GSTC, 2013). 


\section{Ámbitos de actuación para la gestión sustentable de riesgos y crisis en el turismo de Ciudad Juárez.}

\section{Dimensión Científica y Académica.}

El problema de la gestión de crisis en el turismo resulta de gran importancia para Ciudad Juárez por su contribución al desarrollo del turismo frente a diferentes eventos catastróficos. En el orden científico esta problemática se ha posicionado como una necesidad investigativa con el fin de generar información a favor de la solución de los problemas que en la práctica enfrenta el desarrollo del turismo. Deberá constituir una prioridad para diferentes programas científico-técnicos y de desarrollo social, por lo que toda contribución al conocimiento devendrá en alternativas viables sustentadas en posiciones científicas que avalen su introducción práctica en términos más confiables.

Mediante la sistematización científica de la información se podrán generar mensajes con acepciones adecuadas a los diferentes públicos, a la vez que se elaborarán reflexiones teóricas y metodológicas que contribuirán a la multiplicación de saberes cognitivos, procedimentales y actitudinales para la práctica de un turismo seguro ante las crisis, basado en una gestión eficiente. Este será el marco apropiado para establecer con enfoque participativo lineamientos estratégicos que posibiliten dar continuidad autogestionada a cada experiencia con el propósito de extenderla al resto de México. Tales valoraciones deberán contribuir al enriquecimiento de la teoría y la producción científica en materia de gestión de riesgos y crisis en el turismo.

\section{Dimensión Tecnológica}

La situación de riesgos y crisis en el turismo requiere de la implementación y generación de los avances tecnológicos para facilitar de forma efectiva las diferentes etapas de planificación y preparación para eventos de crisis. Al respecto, es de gran importancia el uso de plataformas y herramientas tecnológicas diversas en cada etapa de la gestión. Internet ha creado oportunidades para nuevos modelos de gestión de riesgos y crisis en el turismo, al tiempo que la incorporación de las redes sociales y de los servicios vinculados a terminales de telefonía móvil se estarán convirtiendo en útiles herramientas para tales fines.

\section{Dimensión Social}

Desde el punto de vista social es necesario enriquecer la información y formación de los diferentes actores implicados en la gestión de riesgos y crisis en el turismo, ya que el centro de atención de la problemática se ubica en la dimensión social del turismo como requerimiento básico para el desarrollo sustentable. Al respecto, será oportuno beneficiar a los diferentes 
actores sociales de los espacios turísticos y a las organizaciones que comprende, ofreciendo como beneficios reales las oportunidades de desarrollar fortalezas en la gestión de riesgos y crisis en el turismo, proceso en el cual se deberá propiciar la participación de todos los actores sociales. Esta capacitación repercutirá favorablemente sobre el bienestar social colectivo de los destinos turísticos y garantizará la seguridad para los turistas, las empresas de turismo y los residentes locales.

\section{Dimensión económica}

La planificación preventiva de riesgos y crisis en el turismo impacta sobre el bienestar económico de los destinos/organizaciones reduciendo pérdidas económicas, y desempleo, entre otros, los que repercuten sobre los ingresos económicos y rentas personales, productividad, precios, inversiones, seguridad alimentaria, infraestructura y servicios, etc. Para el éxito en la gestión se requieren políticas eficientes, legislación, regulaciones y control policial, solidaridad humana, estructuras de comunicación y control social, estrategias de prevención y alertas tempranas. La eficiencia de tales instrumentos podrá contribuir a la consolidación de la gestión económica de las crisis en el turismo como atributo de posicionamiento y ventaja competitiva con alto grado de innovación, relacionada con externalidades positivas como la generación de salvaguarda del patrimonio y las riquezas.

\section{Dimensión ambiental}

La gestión está orientada a la optimización de las situaciones de deterioro ambiental generadas por las crisis que afectan el desarrollo sustentable del turismo. Por tal motivo, los impactos de fondo y los impactos potenciales inducidos por eventos de crisis deberán constituir una línea base de actuación. Las soluciones correctivas y preventivas a asumir por cada actor contribuirán a elevar, en términos cuantitativos y cualitativos, la calidad de vida como componente fundamental de una oferta turística que ha de mejorar la imagen de los destinos turísticos, la economía y el desarrollo social de forma integrada a la dimensión territorial ambiental.

\section{Conclusion}

La producción y transmisión de conocimientos relativos a la gestión sustentable de riesgos y crisis en el turismo mexicano y latinoamericano es aún insuficiente. Independientemente de la existencia de marcos institucionales y legislativos que han generado oportunidades favorables y en algunos casos reportado buenas prácticas, la realidad demuestra que es un tema en el que mucho falta por hacer. En particular para México, el Programa Sectorial de Turismo 2013 - 2018 reconoce la importancia de garantizar la seguridad del turista y su relación con un procedimiento 
integrado de gestión de riesgos y crisis, aunque este enfoque parcial dificultaría la actuación integrada y coordinada de forma horizontal/vertical entre todos los actores implicados.

Basado en el estudio realizado se constata que la inseguridad es un factor limitativo para la gestión estratégica de la sustentabilidad de los destinos turísticos y sus organizaciones, esto justifica la propuesta de incorporar el proceso de gestión sustentable de riesgos y crisis en el turismo mexicano y latinoamericano como un problema estratégico para la seguridad de los destinos, al tiempo que resulta oportuno diseminar la información relativa a experiencias que favorezcan el mejoramiento de la preparación y planificación para la actuación ante riesgos y eventos de crisis provocados por la inseguridad de los espacios puestos en valor turístico.

La proyección estratégica sustentable para la mejor preparación y planificación del turismo ante riesgos y eventos de crisis provocados por la inseguridad en Ciudad Juárez está estrechamente relacionada con la imagen actual del destino, el cual es percibido por el mercado como un espacio de turismo fronterizo en un contexto de inseguridad, a pesar de los avances reportados en términos de seguridad turística y reactivación del destino. Al respecto, los hallazgos y experiencias de otros destinos de México y América Latina han permitido de forma participativa la identificación de los ámbitos de actuación y requerimientos mínimos para la gestión sustentable de riesgos y crisis en el turismo de acuerdo con las situaciones de inseguridad percibidas o reportadas. Esto ha facilitado la comprensión propositiva de los aspectos relativos a la situación de inseguridad experimentada a nivel local, el mejoramiento de la capacidad de respuesta ante nuevos eventos de crisis, y la consolidación de la gestión turística para contribuir a la minimización de los efectos adversos a que ha estado expuesto el turismo.

\section{References:}

Agencia Venezolana de Noticias /AVN/. 2012. Más de 782.000 turistas conocieron Venezuela en 2012. http://www.avn.info.ve/contenido/m\%C3\% A1s-782000-turistas-conocieron-venezuela-2012 [recuperado el 21 de 2015]. Aguilar, R. 2015. 14 muertos y tres heridos en 30 horas en Acapulco. Excélsior. 14 de julio de 2015. https://es-mg42.mail.yahoo .com/neo/launch?.rand=dtqora02qbqoi\#1707997335 [recuperado 14 de julio de 2015].

Asociación de Estados del Caribe /AEC/. 1999. Declaración para el Establecimiento de la zona de Turismo Sustentable del Caribe. $2^{\mathrm{a}}$ Cumbre de Jefes de Estado y/o Gobierno de los Estados, Países y Territorios de la Asociación de Estados del Caribe. http://www.acsaec.org/index.php?q=es/documentos/sustainable-tourism/1999/declaracion- 
para-el-establecimiento-de-la-zona-de-turismo-susten [Recuperado el 11 de julio de 2015].

Biosca, Domènec. 2013. La seguridad total del destino turístico, otra clave del éxito del turismo del s. XXI. Barcelona, España. 8 de enero de 2013. http://www.territorioymarketing.com/la-seguridad-total-del-destino-turisticootra-clave-del-exito-del-turismo-del-s-Xxi. [Recuperado el 19 de Julio de 2015].

Blake, Adam and M. Thea Sinclair. 2002. Tourism Crisis Management. Responding to September 11. Nottingham University Business School. http://www.nottingham.ac.uk/ttri

Blancas Peral, F.J.; M. González Lozano; F. Mª Guerrero Casas y M. Lozano Oyola. 2010. Indicadores sintéticos de turismo sostenible: una aplicación para los destinos turísticos de Andalucía. Revista Electrónica de Comunicaciones y Trabajos de ASEPUMA. Volumen 11. Páginas 85-118. http://www.google.com.mx/url?sa=t\&rct=j\&q=\&esrc=s\&source=web\&cd=3 \&ved=0CC8QFjAC\&url=http\%3A\%2F\%2Fdialnet.unirioja.es\%2Fdescarga \%2Farticulo\%2F3674366.pdf\&ei=XmKhVfLvKozdoASG7bqYAw\&usg=A FQjCNGoqZSIs272NxyMkn2UWqLukoEhKA\&bvm=bv.97653015,d.cGU [recuperado el 11 de julio de 2015].

Blog de la Presidencia. 2012. Todos somos Juárez, dos años después. 17 de febrero de 2012. http://calderon.presidencia.gob.mx/blog/felipe-calderon [recuperado el 28 de junio de 2015].

Bringas Rábago, Nora L., y Basilio Verduzco Chávez. 2008. La construcción de la frontera norte como destino turístico en un contexto de alertas de seguridad. Región y sociedad. Vol. XX No.42 Hermosillo mayo/agosto de 2008.

http://www.scielo.org.mx/scielo.php?script=sci_arttext\&pid=S187039252008000200001 [recuperado el 17 de julio de 2015].

Calderón Gutiérrez, Fernando (coord.). 2011. Los conflictos sociales en América Latina. Programa de las Naciones Unidas para el Desarrollo y Fundación UNIR Bolivia. Bolivia, septiembre de 2011.

Cedeño, Luis. 2013. Violencia y criminalidad en el Área Metropolitana de Caracas: situación actual y propuestas de acción. Instituto Latinoamericano de Investigaciones Sociales. Caracas, septiembre de 2013. http://www.ildis.org.ve/website/administrador/uploads/DocumentoViolencia AMCCedeno.pdf [recuperado el 9 de julio de 2015].

Centro de Estudios Superiores en Turismo /CESTUR/ y Universidad Anáhuac México Norte. 2012. Evaluación de desempeño de los destinos turísticos en el marco de los Convenios de Coordinación en materia de Reasignación de Recursos (CCRR). http://www.cestur.sectur.gob.mx/ 
Christmann, Peter and Andreas Gettkant. 1999. Sustainable Tourism as a Development Option Practical Guide for Local Planners, Developers and Decision Makers. Birgit Steck Editor. Germany.

Comisión Económica para América Latina y el Caribe /CEPAL/. 2015a. Economía de América Latina y el Caribe crecería en torno a 1\% en 2015, según nueva proyección de CEPAL. 7 de abril de 2015.

Comisión Económica para América Latina y el Caribe de las Naciones Unidas /CEPAL/. 2015b. Sede Subregional de la CEPAL en México. Área de investigación, Evaluación de Desastres Naturales. http://www.cepal.org/cgi-

bin/getprod.asp?xml=/mexico/noticias/paginas/1/10061/P10061.xml\&xsl=/m exico/tpl/p18f-st.xsl\&base=/mexico/tpl/top-bottom.xsl [recuperado el 19 de julio de 2015].

Comisión Económica para América Latina y el Caribe de las Naciones Unidas /CEPAL/. 2011. Ingresos por turismo representan más de 30\% del PIB para algunos países de la región. 21 de marzo de 2011 | Comunicado de prensa. http://www.cepal.org/es/comunicados/ingresos-por-turismorepresentan-mas-de-30-del-pib-para-algunos-paises-de-la-region [recuperado el 19 de julio de 2015].

Commission on Sustainable Development /CSD/. 1995. Indicators of sustainable development: guidelines and methodologies. Chapter 4: CSD Core Indicator Framework, 4.3.5 Security, page 36 http://www.un.org/esa/sustdev/publications/indisd-mg2001.pdf [recuperado el 11 de julio de 2015].

De Dios Olivas, J. 2013. Acapulco es el municipio más violento de México según Consejo Ciudadano para la Seguridad Pública. Miércoles, 20 febrero 2013. http://elcorreodejuarez.com.mx/dinero/itemlist/user/94-paolacarmona? start=40[recuperado el 21 de julio de 2015].

Department of State. 2015b. Mexico Travel Warming. 05 may 2015. http://ravel.state.gov/content/passports/english/alertswarnings/mexicotravel-warning.html [recuperado el 18 de julio de 2015].

Department of State. Travel.State.gov. 2015a. Alerts and Warnings. http://travel.state.gov/travel/cis_pa_tw/tw/tw_1764.html [recuperado el 18 de julio de 2015].

Edgell, D. L., and J. R. Swanson. 2013. Tourism Policy and Planning. Yesterday, Today and Tomorrow. Second Edition. Routledge. Taylor \& Francis Croup. London and New York. T J International Ltd, Padstow, Cornwall. Great Britain.

Forbes. 2015a. Las 50 ciudades más violentas del mundo. http://www.forbes.com.mx/las-50-ciudades-mas-violentas-del-mundo/ [recuperado el 21 de julio de 2015]. 
Forbes. 2015b. Las 10 ciudades de América Latina más visitadas en 2015. http://www.forbes.com.mx/las-10-ciudades-de-america-latina-mas-visitadasen-2015/ [recuperado el 21 de julio de 2015].

Global Sustainable Tourism Council /GSTC/. 2013. Global Sustainable Council Tourism Criteria for Destinations (GSTC C-D). Version 1.0. November 2013 and Global Sustainable Council Tourism Criteria for Destinations-suggested performance indicators. Version 10. December 2013. http://www.gstcouncil.org/en/gstc-criteria/criteria-for-destinations.html [recuperado el 11 de julio de 2015].

Global Sustainable Tourism Council /GSTC/. 2014. Criteria for Hotels and Tour Operators. Version 2. September 2014. http://www.gstcouncil.org /en/docs/file/365-englisth-h-tov2.html [recuperado el 11 de julio de 2015].

González, Manuel. 2010. Gestión Ambiental en el Turismo y la Hostelería. Editorial CEP S.L. Madrid, España.

Grünewald, L. (Compilador). s/a. Municipio, Turismo \& Seguridad. Universidad Nacional de Quilmes y Organización de Estados Americanos. Edición

Digital. http://portal.oas.org/en/sedi/dedtt/tourism/DOCUMENTS\%20IMPORTANT /Publications/DDECT\%20y\%20Universidad\%20Nacional\%20de\%20Quilme s\%20Publicaci\%C3\%B3n\%20-\%20Municipio-Turismo-y-Seguridad.pdf [recuperado el 16 de julio de 2015].

Ibáñez Pérez, Reyna M. 2010. Sustentabilidad e indicadores de desarrollo turístico en México. TURyDES. Vol. 3. No. 7. Abril-mayo 2010. Grupo de Investigación eumed.net con la colaboración de la Facultad de Turismo de la Universidad de La Habana, Cuba. http://www.eumed.net/rev/turydes /07/rmip.htm [recuperado el 11 de julio de 2015].

Institute for Economics and Peace /IEP/. 2015a. Global Peace Index. Measuring Peace, its Causes and its Economic Value. Sydney, New York and Mexico City. PDF. www.economicsandpeace.org

Institute for Economic and Peace /IEP/. 2015b. El costo de la violencia. Publicado el 17 Jun 2015. http://www.visionofhumanity.org/\#/page/news/ 1191 [recuperado el 9 de julio de 2015].

Institute for Economic and Peace /IEP/. 2015c. Paz en Guatemala. Publicado el 21 Nov 2013. http://www.visionofhumanity.org/\#/page/news/781 [recuperado el 9 de julio de 2015].

Instituto Distrital de Turismo /IDT/. 2010. Primer Encuentro Internacional "Seguridad Turística: Destinos Competitivos y Sostenibles. Gobierno de la Ciudad, Bogotá positiva http://www.bogotaturismo.gov.co/sites/default /files/documento_evento-web.pdf [recuperado el 16 de julio de 2015].

Instituto Guatemalteco de Turismo /INGUAT/. 2015. Estadísticas del INGUAT muestran que durante la semana santa 2014 Guatemala recibió más turistas en relación a las vacaciones del año pasado. 
https://cgnnoticiasdeguatemala.wordpress.com/2014/04/24/mas-turistasllegaron-este-ano/ [recuperado el 21 de 2015].

Instituto Nacional de Estadística, Geografía e Informática /INEGI/. 2000. Indicadores de Desarrollo Sustentable en México. http://www.inegi .gob.mx/prod_serv/contenidos/espanol/bvinegi/productos/integracion/especia les/indesmex/2000/ifdm2000f.pdf [recuperado el 9 de julio de 2015].

Instituto Nacional de Geografía y Estadística /INEGI/. 2015. México en Cifras. Distrito Federal. http://www3.inegi.org.mx/sistemas/mexicocifras/ default.aspx?e=9 [recuperado el 21 de julio de 2015].

Londoño, J. Gaviria, A. \& Guerrero, R. 2000. Asalto al desarrollo: Violencia en América Latina. Washington, DC. Banco Interamericano de Desarrollo.

Montalbán, I. 2009. Paz. Observatorio contra violencia doméstica y género. En: 40 definiciones de paz. El Mundo. Edición España. 22 de marzo de 2009. http://fund-culturadepaz.org/doc/40_Definiciones_PAZ.pdf [recuperado el 18 de julio de 2015].

Moser, C., y J. Holland. 1997. La pobreza urbana y la violencia en Jamaica, Banco Mundial, Washington D.C.

Organización Mundial de la Salud /OMS/. 2002. Definición de Violencia. http://www.who.int/violence_injury_prevention/violence/world_report/es/su mmary_es.pdf [recuperado el 28 de junio de 2015].

Organización Mundial del Turismo /OMT/. 2012. Herramientas de comunicación de crisis en el ámbito del turismo - Listas de verificación y prácticas idóneas http://www2.unwto.org/es/node/37099

Organización Mundial del Turismo /OMT/. 2013. El turismo como inductor del desarrollo, de la inclusión social y de la integración regional. PDF. Parte I y II. 142 pp. http://www.e-unwto.org/

Parametría. 2013. México inseguro, pero recomendable para turistas. Investigación Estratégica, Análisis de Opinión y Mercado. http://www.parametria.com.mx/DetalleEstudio.php?E=4319 [recuperado el 18 de julio de 2015].

Pennington-Gray, L., Schroeder, A., \& Kaplanidou, K. 2011. Examining the Influence of Past Travel Experience, General Web Searching Behaviors and Risk Perceptions on Future Travel Intentions. International Journal of Safety and Security in Hospitality and Tourism, 1(1), 64-92.

Portal Oficial de Turismo de Medellín. 2015. En 2014 Medellín recibió a 549 455 visitantes nacionales e internacionales. https://www.medellin.gov. co/irj/portal/visitantes [recuperado el 21 de 2015].

Rodríguez-Toubes Muñiz, D., y José A. Fraiz Brea. 2010. Gestión de crisis en el turismo: la cara emergente de la sostenibilidad. Revista Encontros Científicos. No. 6. http://www.scielo.mec.pt/scielo.php?pid=S164624082010000100006\&script=sci_arttext [recuperado el 18 de julio de 2015]. 
Rojas Arboleda, Daniel. 2012. Medellín mejoró en ranquin de seguridad. El colombiano. Publicado el 13 de enero de 2012. http://www.elcolombiano.com/medellin_mejoro_en_ranquin_de_seguridadGCEC_165636 [recuperado el 10 de julio de 2015].

Secretaría de Turismo /SECTUR/. 2014. Estudio de Competitividad Turística del destino Acapulco, Guerrero. www.sectur.gob.mx/sub/.../3-Agenda-deCompetitividad-Acapulco.pdf [recuperado el 22 de julio de 2015].

Secretaría de Turismo de México /SECTUR/. 2011. Programa de Turismo Sustentable en México. Dirección General de Planeación Estratégica y Política Sectorial. SECTUR, México. http://www.google.com.mx/url?sa=t\&rct=j\&q $=\&$ esrc $=$ s\&source $=$ web\& $c d=1 \&$ ved $=0 \mathrm{CBwQFjAA} \& u r l=h t t p \% 3 \mathrm{~A} \% 2 \mathrm{~F} \% 2 \mathrm{~F}$ www.sectur.gob.mx\%2FPDF\%2Fplaneacion_estrategica\%2FPTSM.pdf\&ei= hUqhVdmkAYu3oQS3y7KAAw\&usg=AFQjCNFZD9ZFc1Owf65Pm3AAp NlwFk6_sw\&bvm=bv.97653015,d.cGU [recuperado el 11 de julio de 2015]. Universidad Nacional de Quilmes /UNQ/. 2012. Sistema Integral de Seguridad para Destinos y Empresas Turísticas -SISDyET-. http://portal.seguridadturistica.org/ [recuperado el 18 de julio de 2015]. Virgen Aguilar, Carlos Rogelio. 2014. Turismo y desarrollo sustentable. Un acercamiento al estudio del Turismo. AMESTUR. Impreso en México.

Wilks, J. y Moore, S. 2003. Tourism Risk Management for the Asia Pacific Region: An Authoritative Guide for Managing Crises and Disasters. Commonwealth of Australia, APEC International Centre for Sustainable Tourism (AICST).

World Tourism Organization /UNWTO/. 2015. UNWTO Annual Report 2014, UNWTO, Madrid. http://dtxtq4w60xqpw.cloudfront.net/sites /all/files/pdf/unwto_annual_report_2014.pdf [recuperado el 28 de junio de 2015]. 